\title{
Nitrogen distribution under sub surface drip fertigation system on banana cv. RASTHALI
}

\section{YUVARAJ AND P.P. MAHENDRAN}

Received : 14.06.2017; Revised : 02.11.2017; Accepted : 12.11.2017

\section{MEMBERS OF RESEARCH FORUM:}

Corresponding author :

M. YUVARAJ, Department of Soil

Science and Agricultural Chemistry,

Adhiparasakthi Agricultural College,

Kalavai, VELLORE (T.N.) INDIA

Email: yuvasoil@gmail.com

\section{Co-authors :}

P.P. MAHENDRAN, Department of

Soil Science and Agricultural

Chemistry, Agricultural College and

Research Institute, MADURAI

(T.N.) INDIA

Email: ppmahendran2002@

yahoo.co.in

\section{Summary}

The sub surface drip fertigation is a technique to applay both water and fertilizers through drip irrigation system during the recent years were shown to be very effective in achieving higher water and fertilizer use efficiencies. The nutrient mobility study revealed that fertigation treatments maintained higher concentration of available nitrogen around root zone of banana compared to surface irrigation with soil application of recommended dose of fertilizers where most of the nutrients moved to deeper layer due to leaching fraction of applied fertilizers. In general, subsurface drip fertigation of 100 per cent RDF treatments in combination with liquid biofertilizers maintained higher available NPK in the post harvest soil compared to surface irrigation with soil application of recommended dose of fertilizers. Further, drip fertigation integrated with liquid biofertilizers created favourable condition for multiplication of beneficial micro-organisms in the rhizosphere region.

Key words : Subsurface drip fertigation, Nutrient mobility, Nitrogen, Banana

How to cite this article : Yuvaraj, M. and Mahendran, P.P. (2017). Nitrogen distribution under sub surface drip fertigation system on banana cv. RASTHALI. Asian J. Soil Sci., 12 (2) : 242-247 : DOI : 10.15740/HAS/AJSS/12.2/242-247. 